\title{
Molecular Detection and Characterization of Haemobartonella felis in Domestic Cats in Japan Employing Sequence-Specific Polymerase Chain Reaction (SS-PCR)
}

\author{
Masashi WATANABE ${ }^{1}$, Masaharu HISASUE ${ }^{1}$, Kazuko HASHIZAKI $^{1}$, Mitsuru FURUICHI ${ }^{1}$, Munetsugu OGATA ${ }^{2}$, \\ Shin HISAMATSU ${ }^{3)}$, Etsuko OGI ${ }^{4)}$, Masakuni HASEGAWA ${ }^{5)}$, Ryo TSUCHIYA ${ }^{1)}$ and Takatsugu YAMADA ${ }^{1)}$ \\ ${ }^{1)}$ Laboratory of Veterinary Internal Medicine II, ${ }^{2)}$ Veterinary Teaching Hospital, School of Veterinary Medicine, ${ }^{3)}$ Department of \\ Environmental Chemistry, Faculty of Environmental Health, Azabu University, Sagamihara, Kanagawa 229-8501, ${ }^{4}$ Ogi Animal \\ Hospital, Suita, Osaka 564-0024 and ${ }^{5)}$ Hasegawa Animal Hospital, Atsugi, Kanagawa 243-0812, Japan
}

(Received 6 February 2003/Accepted 16 June 2003)

ABSTRACT. A novel PCR assay was developed in order to examine the prevalence of Haemobartonella felis ( $\mathrm{H}$. felis) in Japanese domestic cats and which was able to differentiate of the Ohio strain and the California strain of $H$. felis. Blood samples from a total of 21 cats suspected of having haemobartonellosis were examined employing a novel PCR assay and demonstrated positive results in 18 cats wh ich was confirmed by cytological examination of blood smears. Four out of 18 positive cats $(22 \%)$ were infected with the California strain, whilst the other 12 cats $(67 \%)$ were infected with the Ohio strain and two animals $(11 \%)$ were infected with both strains. As most of the cats with moderate to severe anemia were infected with the Ohio strain, it is suggested that the most prevalent strain of $H$. felis in Japanese domestic cats might be the Ohio strain. In the present study, it was thought that molecular detection and characterization of H. felis may provide valuable information regarding the severity and prognosis of this illness.

KEY WORDS: feline, Haemobartonella felis, 16S rRNA,

J. Vet. Med. Sci. 65(10): 1111-1114, 2003

Haemobartonella felis (H. felis), is a gram-negative and small epicellular bacterial parasite of feline erythrocytes, which is responsible for moderate to severe hemolytic anemia, thrombocytopenia, fever and jaundice and is the causal agent of haemobartonellosis [5]. In particular, naturally occurring haemobartonellosis is often severe and recurrent when cats become co-infected with feline leukemia virus or feline immunodeficiency virus [2,7]. In general, $H$. felis infection can be diagnosed through the detection of the bacterium on the surface of erythrocytes in Giemsa-stained thin blood smear films by microscopic observation [3]. However, it is often difficult to confirm $\mathrm{H}$. felis infection, as the small epierythrocytic parasites may resemble Howell-Jolly bodies or background debris. Previously, it has been shown that the polymerase chain reaction (PCR) technique can detect $H$. felis infection at greater sensitivities $[1,4,9,10]$, although most of these reports describe detection in experimental infections. Hence, it was the main aim of the present study to develop and apply a sensitive and specific novel PCR assay for the detection of $\mathrm{H}$. felis from naturally infected cats. Furthermore, various strains of H. felis, namely the California (GenBank accession no. U88564), Birmingham (GenBank accession no. AF271154), Ohio (GenBank accession no. U88563) and Oklahoma strains (GenBank accession no. AF178677) have previously been reported [6, 11-13] and it is considered that the California and Birmingham strains are very similar morphologically and genetically, whilst the Ohio strain is more closely related to the Oklahoma strain. Hence, it was a further objective of the current study to examine which strain is most prevalent in domestic cats in Japan. Furthermore, we analyzed and revealed the relationship between isolated strains and hematological abnormalities in the cats infected with $H$. felis.

A total of 21 blood specimens (1-2 $\mathrm{m} l$ in EDTA) from an equal number of cats suspected of being infected with $H$. felis infection with the above-mentioned symptoms were obtained from Azabu University Veterinary Teaching Hospital and other veterinary clinics. Parasitemia was estimated by counting the number of parasite-infected erythrocytes per 1,000 cells and a blood sample from uninfected healthy cats was used as a negative control. Genomic DNA of $H$. felis was isolated by the modification of Berent's method [1]. Briefly, after the addition of $500 \mu \mathrm{g}$ lysozyme to $150 \mu \mathrm{l}$ of blood and following incubation for $1 \mathrm{hr}$ at $37^{\circ} \mathrm{C}, 200 \mu \mathrm{g}$ proteinase $\mathrm{K}$ and $100 \mu \mathrm{l}$ of $10 \%$ [w/v] sodium dodecylsulfate (SDS) solution were added and incubated for $10 \mathrm{~min}$ at $65^{\circ} \mathrm{C}$. Following this, $5 \mathrm{M} \mathrm{NaCl}$ solution $(100 \mu l)$ and 160 $\mu l$ of $5 \%[\mathrm{w} / \mathrm{v}]$ hexadecyltrimethylammonium bromide (Sigma Chemical, St.Louis, MO, U.S.A.) were added and incubated for $10 \mathrm{~min}$ at $65^{\circ} \mathrm{C}$, following which, crude DNA was purified by the procedures of phenol/chloroform extraction and ethanol precipitation, as already reported elsewhere. Specific oligonucleotide primers were designed based on the sequence of $H$. felis $16 \mathrm{~S}$ rRNA gene. Two sense primers were designed, one of which was derived from California and Birmingham strains (CA-B2 primer, 5'CTG GGA AAC TAG AGC TTC GCG AGC-3') and the other was derived from Ohio-Florida and Oklahoma strains (OH-Ok1 primer, 5'-ATG CCC CTC TGT GGG GGA TAG CCG-3'). Antisense primer was designed based on homologous regions of all four strains, namely, 00CB-r1, 5'-ATG GTA TTG CTC CAT CAG ACT TTC G-3'. PCR was performed with $10 \mathrm{ng}$ of genomic DNA extracted from cats suspected of having $H$. felis infection, $0.4 \mu \mathrm{M}$ of each primer [CA-B2, OH-Ok1 and 00CB-r1], $1 \times$ PCR buffer, $0.2 \mathrm{mM}$ 
each dNTP, 2.5 units AmpliTaq (Applied Biosystems, Foster City, CA, U.S.A.) DNA polymerase, and sterile water using a temperature gradient thermal cycler (Biometra Analytik Gmbh, Germany), under the following conditions: initial denaturation at $94^{\circ} \mathrm{C}$ for $5 \mathrm{~min}$, followed by 35 cycles of $94^{\circ} \mathrm{C}$ for $45 \mathrm{sec}, 58^{\circ} \mathrm{C}$ for $45 \mathrm{sec}$, and $72^{\circ} \mathrm{C}$ for $45 \mathrm{sec}$. The feline glyceraldehyde-3- phosphate dehydrogenase (FG3PDH) gene was co-amplified as an internal PCR control, using the primers (forward primer: 5' -CCT TCT TGA CCT ACA CTA CAT -3' and reverse primer: 5'-CCA AAG TTG TCA TGG ATG ACC -3'). Optimized cycling conditions for FG3PDH were the same as for $H$. felis PCR, except for annealing at $56^{\circ} \mathrm{C}$ for $45 \mathrm{sec}$.

The age of cats examined was 0.6 to 15 years old and consisted of 11 males and 8 females, but the sex of two cats (Cases 2 and 15) was unknown. Various symptoms were observed, which were anemia (11 cats), anorexia (2 cats), viral infection ( 5 cats), jaundice (1 cat), haematuria (1 cat), renal failure (1 cat), fever and lethargy (2 cats). Moderate to severe anemia $(\mathrm{PCV}<28 \%)$ was seen in 16 cats $(76.2 \%)$. By cytological examination of blood smears, $H$. felis organisms were detected in 18 cats (Cases 1-18), and the parasitemia ranged from $1.1 \%$ to $30 \%$. By microscopic examination of Giemsa-stained blood smears, 18 out of 21 cats were diagnosed with haemobartonellosis due to observing organismlike dots of the correct size and shape on the erythrocytes. Eighteen out of 21 cats $(85.7 \%)$ were positive by PCR, which were confirmed as $H$. felis infection by cytological examination (Table 1). The electrophoretic patterns of the PCR products were shown in Fig. 1. When a 202 bp DNA fragment was amplified, infection with the California strain was suspected, whilst amplification of a 274 bp DNA frag-

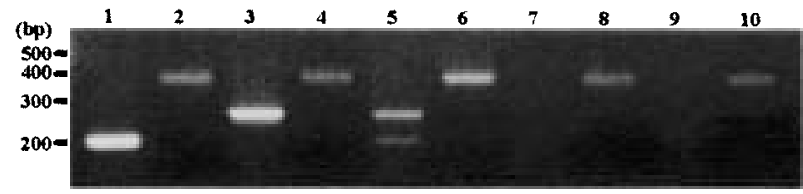

Fig. 1. Results of the PCR assay from four cats suspected of having H. felis infection. Lanes 1 (Case 1) and 3 (Case 5) show amplification of a 202 bp and a 274 bp DNA fragment, respectively. Lane 5 (Case 17) shows the presence of both the $202 \mathrm{bp}$ and 274 bp DNA fragments, indicating a mixed infection of the California strain and the Ohio strain. Lanes 7 (Case 19) and 9 (healthy cat) did not show any amplification. Lanes 2, 4, 6, 8 and 10 represent PCR amplification of feline G3PDH gene as the internal PCR control marker.

ment indicated infection with the Ohio strain. In this study, amplification of the 202 bp DNA fragment was found in 4 cats (Cases 1-4) and amplification of the 274 bp DNA fragment was found in 12 cats (Cases 5-16). Furthermore, both the 202 bp and 274 bp DNA fragments were amplified in 2 cat (Cases 17 and 18). Three cats with anemia were negative by PCR (Cases 19-21). Furthermore, the healthy control population failed to amplify either gene target. Sequence analysis of the $202 \mathrm{bp}$ and $274 \mathrm{bp}$ amplified fragments showed $100 \%$ and $98 \%$ homology with the target region of $16 \mathrm{~S}$ rRNA of $H$. felis, respectively. The $274 \mathrm{bp}$ PCR fragment showed 3 nucleotide changes, which were C to $\mathrm{T}$ transition (nt 165), insertion of $\mathrm{C}$ (nt 185) and deletion of $\mathrm{G}$ (nt 231), compared with the nucleotide sequence of Ohio strain (GenBank accession no. U88563). For determination of the sensitivity of the PCR assay, blood samples

Table 1. Clinical findings and results of PCR assay

\begin{tabular}{|c|c|c|c|c|c|c|c|}
\hline \multirow[b]{2}{*}{ Case No. } & \multirow{2}{*}{$\begin{array}{c}\text { Age } \\
\text { (Years) }\end{array}$} & \multirow[b]{2}{*}{ Sex } & \multirow[b]{2}{*}{ Main symptoms } & \multirow{2}{*}{$\begin{array}{l}\mathrm{PCV} \\
(\%)\end{array}$} & \multirow{2}{*}{$\begin{array}{c}\text { Parasitemia } \\
(\%)\end{array}$} & \multicolumn{2}{|c|}{ PCR assay } \\
\hline & & & & & & $\mathrm{CA}^{\mathrm{f})}$ & $\mathrm{OH}^{\mathrm{g})}$ \\
\hline 1 & 11 & $\mathrm{M}^{\mathrm{b})}$ & FIV $^{\text {d) }}$ infection & 33 & 3.3 & + & - \\
\hline 2 & $\mathrm{ND}^{\mathrm{a})}$ & ND & Anemia & 26 & 1.1 & + & - \\
\hline 3 & 3 & M & Anemia, anorexia & 25 & 5.9 & + & - \\
\hline 4 & 12 & M & Anemia & 32 & 5.0 & + & - \\
\hline 5 & 2 & $\mathrm{~F}^{\mathrm{c})}$ & Anemia & 24 & 17.0 & - & + \\
\hline 6 & 0.9 & M & Haematuria & 33 & 20.0 & - & + \\
\hline 7 & 2 & $\mathrm{~F}$ & Anemia & 22 & 3.0 & - & + \\
\hline 8 & 3 & M & Anemia & 15 & 15.0 & - & + \\
\hline 9 & 2.5 & $\mathrm{~F}$ & Anemia & 11 & 7.0 & - & + \\
\hline 10 & ND & $\mathrm{F}$ & Anemia & 10 & 20.0 & - & + \\
\hline 11 & 1 & M & Anemia, FIV and FeLV $V^{\mathrm{e})}$ infections & 9 & 30 & - & + \\
\hline 12 & 0.9 & $\mathrm{~F}$ & Anemia & 17 & 10 & - & + \\
\hline 13 & 0.6 & $\mathrm{~F}$ & Fever, lethargy & 33 & 9.6 & - & + \\
\hline 14 & 0.6 & $\mathrm{~F}$ & Fever, lethargy & 35 & 1.9 & - & + \\
\hline 15 & ND & ND & Anemia, weakness & 23 & 5.7 & - & + \\
\hline 16 & ND & $\mathrm{F}$ & Anemia, anorexia & 8 & 25 & - & + \\
\hline 17 & ND & M & FIV/FeLV infection & 17 & 10.8 & + & + \\
\hline 18 & 8 & M & Anemia, FIV infection & 16 & 9.1 & + & + \\
\hline 19 & 5.2 & M & Renal failure & 23 & - & - & - \\
\hline 20 & 15 & M & Jaundice & 28 & - & - & - \\
\hline 21 & 3 & M & Anemia & 14 & - & - & - \\
\hline
\end{tabular}

a) Not determined, b) Male, c) Female, d) Feline Immunodeficiency Virus, e) Feline Leukemia Virus, f) California strain, g) Ohio strain. 


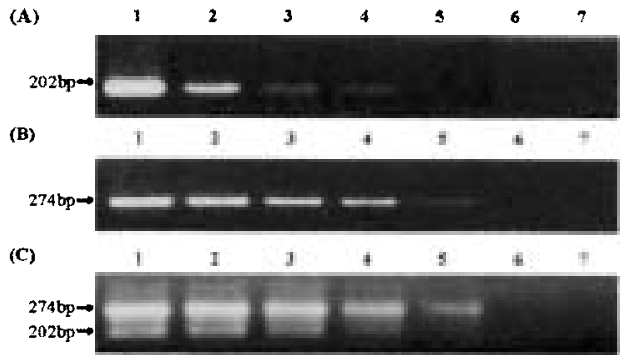

Fig. 2. Sensitivity of the PCR assay in each of the Ohio (OH-OK1 primer) and California (CA-B2 primer) strains of $\mathrm{H}$. felis. Genomic DNA was extracted from 10-fold serial dilutions of feline blood specimens infected with $\mathrm{H}$. felis (Case 3, 5.9\% parasitemia and Case 10,20\% parasitemia). Lanes 1, 2, $3,4,5$ and 6 show $10^{-1}, 10^{-2}, 10^{-3}, 10^{-4}, 10^{-5}$, and $10^{-6}$ dilutions of blood samples, respectively. PCR amplifications were positive until $10^{-4}$ dilution $(0.00059 \%)$ (Fig. 2A, lane 4) employing the CA-B2 primer and until $10^{-5}$ dilution $(0.0002 \%)$ (Fig. 2B, lane 5) employing the OH-Ok1 primer. The sensitivity of PCR for detecting mixed infection (case 18) was estimated to be until $0.000091 \%$ parasitemia (Fig. 2C, lane 6). Lane 7 is a negative control.

obtained from Case 3 (parasitemia: 5.9\%) and Case 10 (parasitemia: $20.0 \%$ ) were diluted with normal PCR-negative feline blood and the diluted samples were amplified by PCR. Thus, detection limits of the parasitemia were estimated to be until $10^{-4}$ dilution $(0.00059 \%$ parasitemia) and $10^{-5}$ dilution $(0.0002 \%)$ with visualization of the $202 \mathrm{bp}$ and 274 bp amplicons, respectively (Fig. 2). Also, the sensitivity of PCR for detecting a mixed infection (Case 18, parasitemia: $9.1 \%$ ) was estimated to be until $0.000091 \%$ parasitemia. Moderate to severe anemia (PCV<28\%) was seen in $13(72 \%)$ of 18 cats infected with $H$. felis infection (Fig. 3, Table. 1). The cats infected with the California strain (Cases 1-4) showed mild anemia or normal PCV and none of these cases had severe anemia. Nine out of 11 cats infected with the Ohio strain (Cases 5-16) had mild to severe anemia. Many of the cats (Cases 8-12 and 16) showed severe anemia $(\mathrm{PCV}<20 \%)$ and the cats infected with both strains showed severe anemia (Cases 17 and 18).

Haemobartonellosis is one of the most important causes of anemia in cats. Diagnosis of this disease is usually based on cytological examination, but historically it has been very difficult to confirm the presence of this parasite [2, 5]. In the present study, the results of the PCR assay were consistent with those of cytological examination, hence it is considered that the PCR assay is a very specific method to detect $H$. felis infection, especially as the PCR assay is able to detect $H$. felis in clinical cases with very low parasitemia (less than 5\%). Westfall et al. indicated that cytological examination could only detect 42 from a total of 112 $(37.5 \%)$ cats with experimental inoculation of $\mathrm{H}$. felis [13]. In the present study, it was not possible to examine cases of

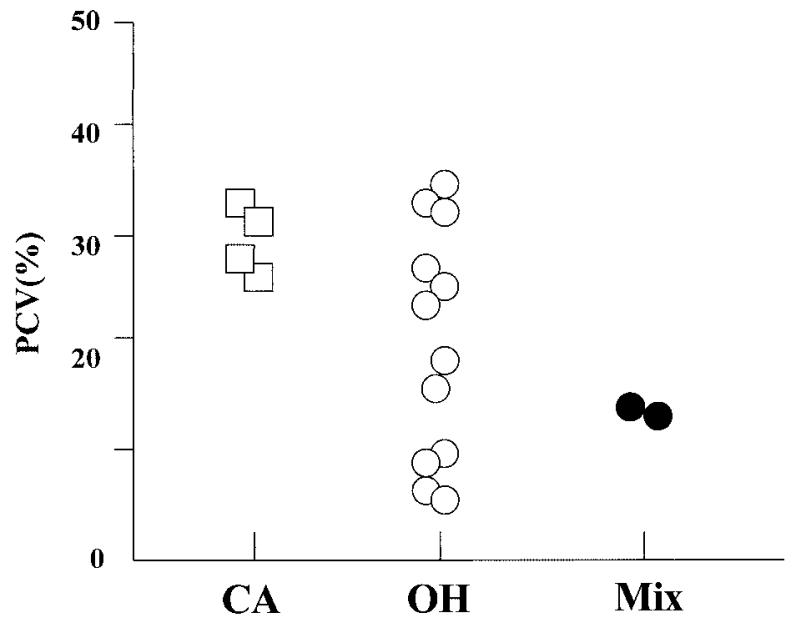

\section{Infected strains}

Fig. 3. Correlation of PCV and the isolated strains in 18 cats with H. felis infection. CA, California strains; $\mathrm{OH}$, Ohio strains; Mix, mixed infection with both $\mathrm{CA}$ and $\mathrm{OH}$ strains. $\square$, cat infected with California strain; $\bigcirc$, cat infected with Ohio strain;

, cat infected with the mixed strains.

suspected H. felis infection without parasitemia, since the sample number examined was moderate. However, in the previous series of published studies with experimental inoculation and other clinical reports, it was reported that the PCR assay could detect $H$. felis infection in those animals without parasitemia in their blood smears $[1,9,13]$. Consequently, further study may therefore be required to confirm the sensitivity and usefulness of our PCR assay with a larger population size. Jensen et al. [9] reported the detection of $H$. felis using a PCR assay employing $16 \mathrm{~S}$ rRNA sequence in naturally infected cats. However, homology of the primers for other organisms was between 90 to $77 \%$. Hence it was the aim of the current study to design primers in silico with less than $75 \%$ homology based on GenBank sequence information, in order to decrease false-priming and hence false positive more so seen in other PCR assay systems, as described previously. The present study demonstrated the presence of the Ohio strain and the California strain in Japanese domestic cats to be $66.7 \%$ and $22.2 \%$, respectively. Two out of 18 PCR positive cats were infected with both strains $(11.1 \%)$, showing severe anemia. In the experimental study, the Ohio strain caused more severe anemia than the California strain, however associated infection with both the Ohio and California strains resulted in a well-developed and marked anemia $[6,8,13]$. In our data, severe anemia (PCV $<20 \%$ ) was observed in cases infected with the Ohio strain, whilst any cases with the California strain present as sole pathogen resulted in moderate anemia (PCV > 20\%) (Fig. 3). Hence, molecular characterization of $\mathrm{H}$. felis isolated from symptomatic cases, may provide valuable information regarding the severity and prognosis of the illness, as well as for monitoring $\mathrm{H}$. felis-infected cats during therapeutic trials. 


\section{REFERENCES}

1. Berent, L. M., Messick, J. B. and Cooper, S. K. 1998. Am. J. Vet. Res. 59: 1215-1220.

2. Bobade, P. A., Nash, A.S. and Rogerson, P. 1988. Vet. Rec. 122: $32-36$.

3. Bobade, P. A. and Nash, A.S. 1987. Vet. Parasitol. 26: 169172.

4. Cooper, S. K., Berent, L. M. and Messick, J. B.1999. J. Microbiol. Method. 34: 235-243.

5. Flint, J. C. and Moss, L. C. 1953. J. Am. Vet. Med. Assoc. 122: $45-48$.

6. Foley, J. E., Harrus, S., Poland, A., Chomel, B. and Pedersen, N. C. 1998. Am. J. Vet. Res. 59: 1581-1588.

7. Grindem, C. B., Corbett, W. T. and Tomkins, M. T. 1990. J.
Am. Vet. Med. Assoc. 196: 96-99.

8. Harvey, J. W. and Gaskin, J. M. 1977. J. Am. Anim. Hosp. Assoc. 13: 28-38.

9. Jensen, W. A., Lappin, M. R., Kamkar, S. and Reagen, W. J. 2001. Am. J. Vet. Res. 62: 604-608.

10. Messick, J. M., Berent, L. B. and Cooper, S. K. 1998. J. Clin. Microbiol. 36: 462-466.

11. Rikihisa, Y., Kawahara, M. Wen, B., Kociba, G., Fuerst, P., Kawamori, F., Suto, C., Shibata, S. and Futohashi, M. 1997. J. Clin. Microbiol. 35: 823-829.

12. Tasker, S., Helps, C. R., Belford, C. J., Birtles, R, J., Day, M. J., Sparkes, A. H., Gruffydd-Jones, T. J. and Harbour, D. A. 2001. Vet. Microbiol. 81: 73-78.

13. Westfall, D. S., Jensen, W. A., Reagen, W. J., Radecki, S. V. and Lappin, M.R. 2001. Am. J. Vet. Res. 62: 687-691. 